\title{
Aspects of Theory and Practice in Dance Movement Psychotherapy (DMP) in the UK: Similarities and Differences from Music Therapy
}

\author{
Dr Vicky Karkou \\ School of Occupational Therapy and Arts Therapies \\ Queen Margaret University \\ Edinburgh Scotland
}

\section{Introduction}

Dance Movement Psychotherapy (DMP) ${ }^{1}$ is the youngest of the $\operatorname{arts~therapies~}^{2}$ with practitioners coming together to form the first professional association in the discipline in the UK in 1982, less than 30 years ago (Karkou and Sanderson 2006). This first group became the Association for Dance Movement Therapy (currently the Association for Dance Movement Psychotherapy UK - ADMP UK) with Helen Payne being the first chair. In comparison, Music Therapy (MT) for example, was first organised as a professional group as early as 1958 by Juliette Alvin; almost 25 years before DMP. DMP is therefore a relatively new profession which is currently used in clinical and non-clinical settings with a wide range of client groups (e.g. people with mental health problems, learning disabilities and medical and/or complex conditions). Although research evidence regarding its effectiveness is growing (Rohrich 2009; Meekums, 2009; Karkou 2009, 2010; see also Quiroga and Kreutz in this book), there is still limited public awareness about what and who DMP is for, what DMP practitioners do and why.

Within the arts therapies field, practitioners agree that DMP has a lot in common with the other arts therapies. According to Waller (Waller 1997 cited in ADMT UK 1997, p.15) for example, all arts therapies share enough between them to be joined together "as a single professional body for regulatory purposes". This position has led to the registration of arts therapists in the same part of the register of the Health Professions Council (HPC), the regulatory body of health professions that is responsible for setting standards of practice and protecting the public ${ }^{3}$. However, until recently clarifying the particular areas that are shared amongst arts therapists has received very little attention; similarly what is distinctive and unique remains unclear.

In this chapter I will therefore, aim to highlight some similarities and differences between DMP and the other arts therapies. I will pay attention to DMP and MT as two particularly affiliated disciplines, and draw, in the first instance, upon existing definitions of the two disciplines. I will also discuss historical influences, key concepts and principles of theory and practice that I regard as pertinent to both

\footnotetext{
${ }^{1}$ The discipline is also known as dance movement therapy. In the USA the term dance/movement therapy is preferred while is certain parts of Europe the discipline is also known as dance therapy.

2 The other three are music, drama and art therapy

${ }^{3}$ At the time of writing this paper, the Association for Dance Movement Psychotherapy UK (ADMP $\mathrm{UK}$ ) has been in the process of completing its registration with HPC as the fourth arts therapy joining the same location of the register that use the umbrella term: 'arts therapies'.
} 
disciplines. Findings from a survey of arts therapists (drama, dance movement, music and art therapists) registered with their professional associations in the UK (Karkou 1998; Karkou and Sanderson 2006) will offer some empirical support to this discussion. It is worth noting that findings from the particular study have already informed the development of benchmark statements for arts therapies (QAA/NHS 2004). As such this chapter will make interesting links with UK policy and expected best practice. Given this all-inclusive-arts therapies starting point, even if my focus will remain primarily upon DMP and MT, other arts therapies will also be mentioned where appropriate.

\section{Definitions}

Dance Movement Psychotherapy (DMP) is defined by the UK professional association as:

"... the psychotherapeutic use of movement and dance through which a person can engage creatively in a process to further their emotional, cognitive, physical and social integration." (ADMK UK 2010, p.1)

Central to this definition is the role of 'movement and dance'. However, as the definition suggests, DMP is not merely about a creative engagement with the medium. Movement and dance are used in a 'psychotherapeutic' manner having a wide, albeit clear, therapeutic direction. This definition implies that DMP is different from dance as an art form, different from community dance and/or dance education. It also highlights links with psychotherapy. These links are not tenuous. Both this definition as well as the recent change of the name of the discipline from Dance Movement Therapy to Dance Movement Psychotherapy ${ }^{4}$ suggests that a large number of practitioners define their practice as a form of psychotherapy.

It is interesting that in the description of Music Therapy (MT) offered by the Association of Professional Music Therapists (APMT), a similar value is placed on ideas and principles stemming from psychotherapy. For example, there is an acknowledgement that there are a number of different approaches to MT but: "Fundamental to all approaches ... is the development of a relationship between the client and therapist" (APMT 2010, p.1) with music-making being the medium through which this relationship is formed. Although within MT literature the term Music Psychotherapy is not that widely used, dance movement psychotherapists and music therapists, along with the other arts therapists, are currently considered as psychotherapists for banding and salary purposes within the National Health Service (NHS 2010).

The similarity between the two definitions offers a first indication that both DMP and MT share some common ground. References to aspects of the history of the two disciplines will bring to the foreground further similarities and highlight differences as we will see in the following section.

\footnotetext{
${ }^{4}$ The change of the name from the Association for Dance Movement Therapy UK (ADMT UK) to the Association for Dance Movement Psychotherapy UK (ADMP UK) has taken place in June 2008. This change corresponds to a respective change of the name of the discipline from a number of DMP practitioners. Still however, the old name (ie dance movement therapy) persists and can be found in publications, websites and some practitioners' professional titles.
} 


\section{Historical influences}

I find that a number of factors enabled the emergence of DMP and MT as modern professions. A first strong influence comes from movements within the arts. Such movements for example, have advocated a shift away from the creation of highly stylised artistic products of the classical era. Halprin (2003) argues that modernism did exactly this, shifted the attention of the artist to natural expressions. She uses a number of examples to illustrate this point. From dance she draws upon Isadora Duncan, the mother of modern dance, who introduced natural movements as a way of adandoning the highly technical ballet vocabulary, while in music she refers to John Cage, who introduced experimentation in silence and sound. Halprin (2003) continues that postmodernism has shifted the process even further away from classical and stylised expressions to questioning them as 'grand narratives' 5 and as such valuing the small, the personal and mundane.

Furthermore, within shifts away from the supremacy of the artist and towards exploring 'natural' and/or 'personal' artistic expressions, permission has been given to both artists and non-artists alike to engage with arts-making processes. This, in turn, has supported artists working in the community and in hospitals and has given rise to movements such as 'the arts for all' and 'the arts for health' (Bunt, 1994, Waller 1991). These movements have highlighted social action, active engagement for all and have had a strong impact on the democratisation of the arts (Landy 2001). Karkou and Sanderson (2006) argue that such movements have also offered a significant leverage to the emergence of arts therapies.

Other important starting points for the arts therapies have come from:

- occupational therapists and the rehabilitation movement for veterans after the Second World War,

- psychiatrists and psychotherapists valuing the power of the arts as alternative means of communication with patients who were difficult to engage in verbal or other type of therapy and

- arts educators finding that child-centred education was largely about children's emotional and social being and as such very closely linked to therapy.

(Karkou and Sanderson 2006)

Over the years, attempts have been made to bring the different arts therapies together. For example a movement for the study of all four arts therapies was initiated in 1977 by Anthony Storr $(1920$ - 2001) and was connected with the Sesame Institute (Jones 1996). However, these movements were not fruitful. Separate developments remained the norm and continue to be so, despite the fact that, as I mentioned before, arts therapists are currently registered under the same professional umbrella within HPC. In order to achieve their registration, they are also expected to have been

\footnotetext{
5 This is a term first introduced by Lyotard (1979) in his seminal book 'the Postmodern Condition' and referred to cohesive explanations of historical events but also of knowledge as a whole. A meta narrative or grand narrative is often associated with modernity, while postmodern positioning often implies questioning such cohesive and all encompassing explanations of the world as leading to exclusion of difference. Instead, 'micronarratives' are valued in ways in which different perspectives and thus different 'truths' can co-exist.
} 
educated in validated and accredited two-year Masters programmes that are often located at a University and/or receive validation from a Higher Education Institution.

Next to these common starting points, in the case of DMP and MT it is also interesting to highlight a few key differences, as I see them:

The role dance as an art form has played in the UK has been very different from music. The former has traditionally held a less prominent place that the latter. This has impacted upon the development of DMP and MT respectively with the former, for example, being delayed in reaching the point of professionalization (see earlier comments regarding 25 years of difference between founding the professional association in DMP compared to MT). Karkou and Sanderson (2006) trace negative connotations associated with dance and the use of the body from ideas originated by Plato. In the Middle Ages the same ideas were adopted by Christianity and further highlighted in the Renaissance era by Descartes' dualism. Looking at recent times, Sanderson (1996, 2000) and Meekums (2000) argue that negative connotations of dance can also be linked with the perception of dance as a primarily female and thus frivolous activity. It is possible that the growth of feminism and feminist studies, input from social and humanistic psychology (e.g. in Gestalt, see Perls, Hafferline and Goodman 1969), body psychotherapy (e.g. Reich 1960) as well as recent challenges of the Cartesian dualism by neuroscience (Damasio 1994, 2000; Giacomo Rizzolatti et al 1996; Gazzola et al 2006) have offered new ways of looking at and perceiving the body, movement and dance. This, in turn, has direct implications for the value placed not only on dance as an art form but also on applied uses of dance and movement as is the case with therapy.

Still, the change of the name of the discipline from Dance Movement Therapy to Dance Movement Psychotherapy in 2008 (ADMT UK 2007a and b) indicated a further need for value and recognition. Arguments put forward for the change of the name of the discipline from 'therapy' to 'psychotherapy' included the idea that as a form of psychotherapy it can be taken seriously. It is interesting that lengthy discussions preceded this change with arguments put forward to remove the word 'dance' from the title of the discipline altogether. Although this change was finally outvoted, the discussion itself can be seen as an indication that negative connotations associated with dance still persist.

In contrast, I find that music has had a very different reception. Within the $20^{\text {th }}$ century for example, physicians have seen music as an agent for benign and potentially therapeutic outcomes. Both Bunt (1994) and Tyler (2000) testify how this has led to extensive experimental work on the 'sedative' effects of music, while encouraging the use of music as a recreational activity within hospital environments. Although similar uses of dance in hospitals have been reported (Meier 2008), it is possible that they have not received as much attention as music-related activities. Moreover, to date, I have found that hospital-based work remains a less accessible place for dance movement psychotherapists (Karkou 1998). Rather, there are strong influences upon the field from educational dance and Laban (Payne 1992). It is possible that within mainstream and special schools dance movement psychotherapists found more receptive colleagues who understood the need to address the child as a whole and attempt to support his/her emotional and social needs through movement and dance (Karkou and Sanderson 2000, 2001). 


\section{Key features of current practice}

A study of professional definitions and relevant literature in the arts therapies has revealed that there are some key features of current practice shared across disciplines (Karkou and Sanderson 2006). These features seem to be common for all arts therapies and include:

- the role of the arts within sessions

- the role of creativity

- imagery, symbolism and metaphor and

- non-verbal communication

Although the list is not exhausted, I find these ideas to be particularly important for both DMP and MT practice ${ }^{6}$.

The role of the arts

Within both DMP and MT, movement/dance and music are seen as key agents for therapeutic change and are defined in a very wide manner. Music-making may refer to a piece of music with a clearly organised form, but more often it refers to the client striking a drum or making noise in what can be seen as a random way (Pavlicevic 1997). Similarly, in DMP dance can be associated with people potentially engaging in both clearly defined and highly choreographed pieces as well as in looking at the meaning of gestures, postures or simple movement (Payne 1992). As mentioned earlier, this way of defining music and dance fits within modern and even more within postmodern practices in the arts as:

(i) it allows for both the skilful and unskilled to be present

(ii) it leads to inclusive (both .... and...) rather than exclusive (either ... or ...) practices.

Other important aspects of the role of the arts within arts therapies as I see them are:

- practitioners seem to pay attention to the arts-making process as opposite to attending to the artistic outcome (Bunt 1994; Shreeves 2006; Landy 2001)

- there is an underlying belief that engagement in the arts stems from an early pre-verbal place and as such constitutes a deeply felt form of knowing (Pavlicevic 1997; Payne, 1992). These ideas echo views in child psychology (Trevarthen and Aitken 2001), in body psychotherapy (Reich 1960) and in recent findings from neuroscience (Damasio 1994, 2000; Giacomo Rizzolatti et al 1996; Gazzola et al 2006)

- there is an assumption that the arts involve the person as a whole (Dosamantes-Beaudry, 1997; Bruscia 1988).

- the arts can be powerful; as such they can lead to transformative or even potentially damaging results, especially in the case of vulnerable clients (Karkou and Glasman 2004). The need for appropriate arts therapies training is therefore often highlighted (Payne 1992; Bunt 1994; Karkou and Sanderson 2006).

\footnotetext{
${ }^{6}$ Note that all arts therapies also rely heavily on the development of a therapeutic relationship, a clear therapeutic contract with a more or less explicit aim/s and an ongoing evaluation of the therapeutic process and outcomes. Some of these ideas are embedded in the therapeutic frameworks adopted by practitioners and discussed in the following section.
} 


\section{Creativity}

Creativity is so central to the field that arts therapies are also known as 'creative arts therapies'. I have defined creativity elsewhere (Karkou and Sanderson 2006, p. 53) as "the capacity to find new and unexpected connections, new relationships and therefore new meanings" (adapted from Stanton-Jones 1992 and Smitskamp 1995). Based on this definition, creativity does not require originality and/or something entirely new but relies on what is already in place. In arts therapies creativity is therefore, seen as a capacity that can be cultivated in all and can be therapeutic in itself. Winnicott (1971) for example values the therapeutic potential of creativity so much that regards it as an indicator of mental health. Finding ways in which to support clients to engage with artistic media 'creatively' is an important part of the therapeutic process in all arts therapies including DMP and MT. For example, offering a safe and non-judgemental environment is important for creativity to emerge. As Malchiodi (1998) argues, creating such an environment is an essential part of the role of the arts therapist.

Closely linked with creativity are some other important features of arts therapies, that is imagery, symbolism and metaphor.

\section{Imagery}

First of all, imagery refers to inner representations of objects and events that are created at will (Walrond-Skinner 1986). I find that imagery is often used in connection with imagination. As Gordon (1987) puts it, the two terms have a similar relationship as still pictures have with moving pictures, ie a film. Imagery provides the still pictures, while imagination stands for the whole of the film. And similar with watching a film, through imagination, people can experience and enjoy an 'inner film', while at the same time be able to critically evaluate it.

Within DMP, imagination is supported in a number of ways. Dosamantes-Alperson (1981) suggests some essential steps to activate kinetic imagination that involve:

- becoming receptive through relaxation

- paying attention to subtle physical sensations

- allowing the imagination to unfold in movement and

- eventually finding words to discuss these experiences

Similar steps towards engaging clients' imagination can also be seen in Bonny's (1994) approach to MT known as Guided Imagery and Music (GIM). However, unlike the active engagement of the client in the movement-making process in DMP, in GIM the therapist seems to be the active creator of the music. Still, clients' own imaginative process is placed in the centre of the process as a transformative experience.

\section{Symbolism}

While imagination is often associated with internal and intrapersonal processes, I regard symbolism is referring more readily to relational/interpersonal processes. Walrond-Skinner (1986) defines it as: “... the representation of an ... idea or wish ... by something else that either possesses analogous qualities or comes to stand for this idea or wish due to consistent associations." (p. 338) 
Understanding the meaning of symbols is important within the therapeutic process (Pavlicevic 1997) and can be explored in a number of different ways. For example, through:

(i) social and/or cultural conventions; for example through using Freudian or Jungian theory or

(ii) what Jones (1996) calls a 'local dictionary', that is the phenomenological experience of the client in the particular time and place

While the first type of meaning is often associated with a search for 'universal' truths, the second tends to value to specific, the personal and the 'unique truth' of the client's experience there and then.

Metaphor

Metaphor is also an important concept for arts therapists to such an extent that Meekums (2002) for example, places it at the heart of DMP practice as a central tool. According to Walrond-Skinner (1986) metaphor is defined as follows:

"Metaphor is an indirect method of communication by which two discrete elements are juxtaposed, the comparison between the two serving to create new meanings... Within symbolism, the symbol represents something else; with a metaphor it is said to be something else" (Walrond-Skinner 1986, p. 213)

I find symbolism and metaphor as relevant to both DMP and MT practice because:

- They allow for 'as if' situations to emerge which are less threatening than dealing with the actual problem.

- They allow for unearthing deeply rooted issues and/or problems

- They encourage people to engage with abstract thinking and elusiveness which can be useful for people who operate with concrete thinking only.

- They allow for multiple meaning to emerge as they lend themselves for several readings of the same thing.

- They are closely linked with creativity and thus can enable creative solutions to emerge.

Non-verbal communication

Focusing on body postures and gestures as well as the moving body is central to DMP because of its potential to communicate without using words. Similarly, the use of music, sound or vocalisations can be the main emphasis of the music therapist as a means for non-verbal communication. This has already been explored in other chapters in this book (e.g. Quiroga and Kreutz). I find that in both DMP and MT as well as the other arts therapies, non-verbal communication can take place in three levels:

- The internal, which deals with emotions and intrapersonal processes within the person and it is closely linked with imagery and imagination

- The dyadic, which deals with two people interacting and thus the interpersonal; in the case of arts therapies this interaction often relies on symbols, metaphors and other creative/artistic media

- The group, which refers to social processes, may have a regulatory or preservation function and a sense of direction; in arts therapies group nonverbal communication also relies heavily on artistic, creative, symbolic and/or metaphoric communication. 
In all cases particular attention is paid not only on what the content of this communication is but also how this communication takes place. Dance movement psychotherapists for example, often refer to Laban's term 'effort' which stands for the quality of one's movement and refers to the emotional intention associated with this movement (Koch and Brauninger 2006; Koch and Bender 2007). Effort is about how something is carried out rather than what is done. Similar attention to the quality of the musical interaction can take place within MT; this interaction can lead to a musical dialogue and form the basis for a client-therapist relationship. The way the artistic interaction unfolds, the relationship is understood and the therapeutic process is guided and safeguarded relies heavily on adopting therapeutically sound frameworks.

\section{Therapeutic frameworks}

Looking at the different therapeutic frameworks available in the arts therapies literature, it is clear that there is an enormous amount of diversity. In an attempt to identify common patterns of practice as they emerged from the field and discover important differences, a survey of practitioners in the UK has been completed (Karkou 1998; Karkou and Sanderson 2006). The survey used a questionnaire that was developed based on interviews with 12 'key informants', that is experts from the four disciplines of arts therapies. Statements collected from these interviews referred to theory, clinical methodology and assessment/evaluation and comprised a large part of the questionnaire. The questionnaire was subsequently disseminated to all registered arts therapists in the $\mathrm{UK}(\mathrm{N}=580$, a response rate of $39 \%$ of the total population).

Six therapeutic trends were revealed as relevant to all arts therapists:

- the humanistic

- the eclectic/integrative

- the psychoanalytic/psychodynamic

- the developmental

- the artistic/creative and

- the active/directive

These trends were the result of statistical analysis of 580 responses of practising arts therapists to more than 100 statements rated on a scale of 1 to 5 ( $5=$ strongly agree to $1=$ strongly disagree); factor analysis was performed on these items that related to theory, clinical methodology and assessment/evaluation. Although all six factors that emerged from the factor analysis received high scores, the factors I named humanistic, eclectic/integrative, and psychoanalytic/psychodynamic were particular relevant to both DMP respondents (7.1 of the total sample) and MT respondents (21\%). Certain characteristics of all of these groups of statements (factors) and their corresponding therapeutic trends are presented in the following sections.

Humanistic

Examples of the statements included in the humanistic factor are:

- "What I am working towards is a sense of self-responsibility

- The purpose of the therapy has to do with the 'wholeness'. 
- One of my fundamental hypotheses is that there is a strong body-mind relationship.

- I am trying to respond with my whole self."

(Karkou and Sanderson 2006, p. 77)

These statements appeared to be closely connected with the humanistic school of thought and received strong agreement amongst both DMP and MT respondents. This was in accordance with DMP literature that makes regular references to childcentred education and ideas that value wholeness and the body-mind relationship (Karkou and Sanderson 2006). 'Humanistic-oriented therapists' (dance movement or verbal psychotherapists alike) often talk about the need to follow the lead of the client and create an 'I-You' or 'real' relationship (Clarkson 1994, p.37), that is a relationship between the client and therapists that has an equal power dynamic and is guided by mutual respect. Clear links between this 'humanistic' trend and DMP practice can be found in the approach developed by Marion Chace (Chaiklin and Schmais 1986) who, at the time when DMP was emerging as a separate discipline in the USA, was strongly influenced by Sullivan, the founder of interpersonal psychotherapy. Her work was closely connected with patients faced with long-term mental health problems such as schizophrenia and lengthy institutionalisation. Given the influence of humanistic thinking upon Chace's work, dance was perceived as expressing an innate need to communicate and thus the aim of therapy was to enable such communication to take place.

In MT literature, references to humanistic therapeutic frameworks can also be found. Bunt (1994) for example, acknowledges that his approach is closely linked with humanistic thinking. He also argues that humanistic/existential ideas are particularly relevant to working with people with terminal illnesses, cancer and so on.

Psychoanalytic/psychodynamic

Next to humanistic thinking, psychoanalytic/psychodynamic ideas are also strongly influential upon DMP and MT practice. For example, some of the statements that fell under the psychoanalytic/psychodynamic factor are:

- "I do analyse in a psychoanalytic way.

- I am trying to link the client's past with their present lives.

- I am looking at the transference between client and therapist.

- Psychoanalytic theory provides me with an explanation of what is going on in the session."

(Karkou and Sanderson 2006, p. 79)

For dance movement psychotherapists, acknowledging unconscious processes and encouraging the client to work with their inner self has been introduced by Mary Whitehouse (1979), originally a dance teacher and Jungian analyst who adopted and adapted key Jungian ideas for movement experiences. Mary Whitehouse (1979) encouraged kinaesthetic awareness, worked with polarities, supported active imagination and authentic movement and highlighted the therapeutic relationship and intuition. The links of this work with Jung are very clear.

Since Whitehouse's time there are further and diverse influences from the psychoanalytic/psychodynamic school of thought upon DMP practice. There are approaches that combine movement analysis and psychoanalytic thinking (Kestenberg 
1975), movement patterns and object relations theory (Siegel 1984), in group work (Sandel and Johnson 1983) or in individual therapy (Penfield 1992). In all cases, the 'transferential' relationship is valued as one that enables clients to relive and rework older ways of relating to significant others in the safety of therapy (Clarkson 1994, p. 32).

Very similar to the input made by Mary Whitehouse in DMP has been the input of Mary Priestley in MT. Priestley $(1975,1995)$ was amongst the first music therapists to seek conceptual understanding of her work through a psychoanalytic perspective. Although her approach, known as analytical MT, became more popular in the USA, in the UK it triggered a number of different developments that have clear references to psychoanalytic/psychodynamic thinking (e.g., Levinge 1993; Odell-Miller 2000, 2002).

Developmental

In the survey of practitioners referred to here, a broad developmental therapeutic framework also emerged as relevant to the work of arts therapists. For example, statements like the following emerged:

- "I hold developmental stage in mind most of the time

- The objectives are linked to the developmental stage the client is at"

(Karkou and Sanderson 2006, p.83)

The developmental framework seems to be in accordance to relevant literature in DMP which highlights strong influences from Laban and Laban-based models of movement development (Laban 1975; Sherborne 1990). Developmental models can also be found extensively within MT; the focus in this case is often on musical development (Hargreaves 1982; Swanwick and Tillman 1986).

Both dance movement psychotherapists and music therapist also appeared to draw upon early psychoanalytic/psychodynamic models of development as a way of understanding their work with their clients. For example, Kestenberg (1975) looks at Laban's movement framework and connects it with Freudian psychosexual development; Siegel (1984) draws upon object relations theory and Klein in particular for her developmental DMP approach; while Levinge (1993) relies on Winnicott for her understanding of the MT process with her work with children. In these cases, either offering 'reparation' or a 'developmentally-appropriate' relationship becomes the aim of the therapeutic process (Clarkson, 1994, p. 34).

\section{Artistic/creative}

Artistic/creative ideas seemed to also remain strongly embedded within arts therapies practice with statements like the following emerging:

- "The therapeutic process is always about encouraging clients to do something

- I try to enable clients to really engage with the art process as fully as possible"

(Karkou and Sanderson 2006, p. 89)

Furthermore, the literature suggests that there are particular artistic/creative models in the field that draw extensively upon the arts as art forms, value creativity as a therapeutic model that can guide and support the process and ultimately encourage clients to become artists. Within DMP for example, Meekums $(2000,2002)$ describes a creative approach to therapy in which the therapeutic process closely resembles the 
creative process. Creative approaches to MT are often connected with the NordorffRobbins school of thought (Nordorff and Robbins 1971, 1977), where music and music-making appears to play a central role in the therapeutic process.

Active/directive

A factor called active/directive was also revealed through the factor analysis which included the following statements:

- "Sometimes I will actively do artwork myself during the session

- I may concentrate my work on physical aspects

- I do direct more than just for basic safety

- I do have certain techniques that I bring out when it is appropriate."

(Karkou and Sanderson 2006, p. 91)

This group of statement seems to refer to a number of different ways of approaching therapeutic work:

(i) the therapist may be actively involved in the session as a way of guiding the artistic work

(ii) $\mathrm{s} /$ he might be 'directive' in terms of introducing particular techniques as seen appropriate

(iii) s/he might hold specific aims and objectives that can be fairly narrow. The discussion about the degree to which there is more or less direction within the sessions and more or less structure is pertinent as revealed in relevant arts therapies literature (Liebmann 1986; McNeilly 1983; Bruscia 1988; Oldfield 1995).

The needs of the clients, the duration of the intervention and the theoretical orientation of the therapists seem to play a key role in the decision of how much structure and direction should be offered. For example links with short term therapy and behaviourism can often be made when active/directive approaches are introduced. Examples of working within behavioural thinking can be found in MT in the USA (Standley 1991; Thaut 1985) and less often in the UK (Wigram 1996; Wigram and Dileo 1997). However, such models do not appear to have become popular amongst neither DMP nor MT practitioners. Therefore, it is not surprising that this set of statements had the lowest score indicating that respondents to the survey showed the weakest agreement with these ideas.

As pressure to engage with such models is becoming increasingly relevant within a competitive job market that values short term interventions and behavioural approaches (e.g. CBT), DMP and MT practitioners are often forced to engage with such approaches. It is possible that further consideration is needed on how best to respond to such pressures.

\section{Eclectic/integrative}

Finally, and unlike the active/directive group of statements that received the least agreement amongst arts therapists, the eclectic/integrative set of statements scored fairly high amongst DMP and MT respondents. Some of the statements included in this set were:

- "I use a number of different approaches for each client

- It depends which population I am working with, what sort of theoretical approach I am adopting 
- I do not think that I have one model that I follow."

(Karkou and Sanderson 2006, p. 96)

The above statements suggest the presence of flexible work that adapts to the needs of client groups and clients. Although, eclectic/integrative approaches have been criticised as potentially being atheoretical and bearing the danger of lumping together ideas that may clash (Abram 1992; Thorne 1967; Valente and Fontana 1993), their relevance to DMP and MT remains pertinent. Within DMP for example, Payne (1994) argues for the value of eclectic/integrative approaches. In MT the interactive (or free improvisational) MT approach that began with Juliette Alvin and the Guildhall training programme draws heavily upon a number of different psychotherapeutic schools of thoughts. According to Wigram, Pedersen and Bonde (2002), Alvin's approach is closely linked with an eclectic approach to MT as it incorporates medical, recreational, educational, psychological and musical perspectives.

Eclectic/integrative approaches retain memories of the range of the original influences and bodies of knowledge that have come together to form arts therapies as modern professions (Karkou and Sanderson 2006). They also allow for contemporary ideas to be incorporated within current practice such as postmodern ideas stemming from sociology and the arts (Gergen 1985, 1991; Grentz 1996; Lyotard 1979). Within DMP these ideas have been further developed by Best (2000), Best and Parker (2001) and Allegranti (2009), and have close affiliation with social contructionism in particular. In MT, Pavlicevic (1997) makes references to postmodernism, while similar discussion can be found in the wider arts therapies literature (e.g. Byrne 1995; Karkou and Sanderson 2006; Karkou, Martinsone and Nazarova 2010). Within a postmodern framework, being flexible and in flux is an expected state. Both the definition of the self, the social context within which one is located and the usefulness of therapeutic interventions are seen as having such fluidity and needing to be constantly defined and redefined.

According to Byrne (1995), the postmodern self is faced with the danger of fragmentation (Byrne 1995). Similarly, a postmodern view to DMP and MT might bear similar danger because:

- As a reactionist approach to existing theories, is limited in terms of its ability to suggest something new

- It remains poor in terms of full conceptualisations of a therapeutic model; postmodernism has derived from sociology and the arts, not therapy

- Can allow for far too much diversity to the extent that 'everything might go'.

Within a constant state of flux, knowledge of existing practices and clear definitions of guiding principles are vital for the development of coherent, yet flexible, professional identities that accounts for core practices and their variations.

Some variations of practice

The survey of practitioners (Karkou 1998; Karkou and Sanderson 2006) revealed that statistically significant differences existed between responses from DMP and the other arts therapies in that dance movement psychotherapists showed stronger agreement with the humanistic group of statements (accepted at a 0.05 level of significance). 
This was probably the result of historical links of DMP with child-centred education and the contribution of Laban and creative educational dance, as well as the value placed on the body by humanistic and body psychotherapies referred to before.

The same study also showed that there were statistically significant differences between MT and the other arts therapies regarding the humanistic, the eclectic/integrative and the psychoanalytic/psychodynamic trends (accepted at a 0.01 level of significance) with the former showing weaker agreement with these trends than the latter. It appeared that the music therapists who participated in the study were more sceptical about these therapeutic frameworks than other arts therapists. This might be the result of music therapists attempting to define their work from within and thus without borrowing therapeutic frameworks and/or making external references to psychotherapy, psychology, sociology and/or the arts.

Finally, some additional variations of practice can be found in relation to working environments and client groups. For example arts therapists including DMP and MT practitioners working in the health service often drew more heavily upon psychoanalytic/psychodynamic frameworks than when they were located in other settings (Karkou 1998; Karkou and Sanderson 2006). It is possible that within hospitals, psychoanalytic/psychodynamic thinking can be more readily understood than, let's say humanistic or artistic/creative ideas. Furthermore, with clients who are psychologically unwell and thus need to be inpatients, psychodynamic thinking can offer a solid theoretical framework for the therapist to make sense of the needs of the clients and the therapeutic process.

Regarding client groups, when arts therapists were working with adults with mental health problems, they preferred psychoanalytic/psychodynamic ideas as most relevant to their practice (Karkou 1998; Karkou and Sanderson 2006). Working with clients with learning difficulties, developmental, artistic/creative and active/directive therapeutic ideas were particularly relevant, albeit there was only weak statistical support for this. Finally with clients with no apparent difficulties, humanistic and artistic/creative perspectives were particularly relevant. It appears that the needs of the clients are taken seriously on board and as such diverse needs lead therapists to ascribe value and usefulness for their practice to equally diverse therapeutic frameworks.

\section{Conclusions}

In this chapter I have argued that DMP is a growing field with clear links with MT; also with clear and distinct differences.

First of all, they both belong to the same family of arts therapies and in many ways I see practitioners defining their work in similar ways, while sharing similar standards for training and agreed requirements for professional practice and registration. I have also argued that different views of the value of music over dance, stemming primarily from a Cartesian dualism and the association of dance with the low status of women, have delayed the development of DMP as an organised profession.

Furthermore, I find that both DMP and MT, along with other arts therapies, share some key feature of practice such as the way they view and use the arts, the central 
role of creativity, imagery, symbolism and metaphor, the significant place of nonverbal communication in the development of the client-therapist relationship and in the transformative aspects of the therapeutic process. As these are concepts primarily emerging from a review of relevant definitions and the literature, it is not clear how much they are indeed used by DMP and MT practitioners. Further empirical work is needed to ascertain these and any other key features are shared across these two disciplines.

Finally, and unlike the previous theoretical ideas, empirical findings from a survey of practitioners in the UK, revealed that arts therapists including dance movement psychotherapists and music therapists, are in overall agreement with the use of certain therapeutic frameworks, that is humanistic, psychoanalytic/psychodynamic, developmental, artistic/creative, active/directive and eclectic integrative. Variations of practice exist based on client groups and settings, but also based on the type of arts therapies considered. For example, DMP practitioners appear to be in stronger agreement with humanistic ideas, while MT practitioners seem more sceptical with adopting therapeutic frameworks borrowed from outside the MT discipline itself.

Further work is needed in terms of:

1. Professional identity.

It appears that there is a need for the development of stronger professional identities that remain fluid and flexible. A shift away from relying heavily on therapeutic frameworks that have not emerged from within arts therapies practice might also be needed as this shift can question the prevalence of 'grant narratives' found in modern psychotherapy. Calls for valuing the development of theoretical justifications of arts therapies practice from within the discipline have already been made in DMP (Meekums 2002) and other arts therapies (Jones 1996).

Ways in which professional identities might be strengthened include clear mapping of what is already there and identifying needs and gaps. Calls to expand mapping of the field of arts therapies across disciplines with particular client groups have already being made. One such example comes from Burns (2008) who identified patterns of practice across arts therapies in dementia care and developed useful 'thick' descriptions of current practice. Such comparisons can also take place across countries. For example, arts therapists in Russia, and Latvia have taken this challenge on (Karkou et al 2010; Martinsone, Karkou and Nazarova 2009) aiming to identify 'cultural borrowing' and learn from each others' differences. Looking at the way different arts therapists work could enable practitioners to learn from each other and ultimately offer better care.

\section{Development of evidence-based practices.}

Although research evidence from both DMT and MT is growing (see relevant chapters in this book such as Quiroga and Kreutz, and Wigram), practice that is clearly informed by existing research evidence is not widely available. Furthermore, practitioners often engage with unique and innovative ways of working which are potentially useful for clients, but miss out from thoroughly evaluating their work through engaging clients in the process, considering active improvement of practice and disseminating any benefits to a wider audience. Engagement in evidence-based practice and practice-based evidence are key areas for further development in the area within the current postmodern climate of flux and instability. 


\section{Collaborative work}

Collaborative work is needed regarding resources, training and practice between DMP, MT and the other arts therapies. Examples from collaborative projects involving arts therapists from different disciplines can be found in Karkou, Fullarton and Scarth (2010) and Meekums, Karkou, Elefant et al (2010). These however, remain the exception rather than the norm. Such collaborations can expand beyond the field of arts therapies and create connections with artists and caring professions in ways that build bridges between professions. Ultimately collaboration will place clients in the centre of their own recovery and enable the development of agreed care pathways that offer cohesive and potentially transformative experiences.

\section{References}

Abram J (1992) Individual Psychotherapy Trainings: A Guide. London: Free Association Books.

Allegranti, B (2009) Embodied Performances of Sexuality and Gender: A feminist approach to Dance Movement Psychotherapy and Performance Practice, Body, Movement and Dance in Psychotherapy, Vol. 4, No. 1, April 2009, 17-31

Association for Dance Movement Therapy UK (ADMT UK 1997) 1997 UK news: Council for Professions Supplementary to Medicine (CPSM): about the setting up of the Arts Therapies Board, E-motion. ADMT UK Quarterly, IX (2): 15.

Association for Dance Movement Therapy UK (ADMT UK 2007a) News from ADMT UK Council, e-motion, spring, XIV, 19, 3-4.

Association for Dance Movement Therapy UK (2007b) News from ADMT UK Council, e-motion, autumn, XIV, 21, 3.

Association of Professional Music Therapist (APMT) (2010) What is Music Therapy? Retrieved: 01/10/10 From: http://www.apmt.org/Info/MusicTherapy/tabid/69/Default.aspx

Best P (2000) Theoretical Diversity and Clinical Collaboration: Reflections by a dance/movement therapist, The Arts in Psychotherapy, 27, 3, 197-211.

Best P and Parker G (2001) Moving Reflections: the Social Creation on Identities in Communication. In Kossolapow. L Scoble, S and Waller D (eds) Arts - Therapies Communication: On the Way to a Communicative European Arts Therapy, vol 1, Lit Verlag, Munster, pp.142-148.

Bonny, H (1994) Twenty-One years later: a GIM update, Music Therapy Perspectives, 12 (2) 70-74.

Bruscia, K. E. (1988) A survey of treatment procedures in improvisational music therapy, Psychology of Music, 16, 10-24. 
Bunt L (1994) Music Therapy: An Art Beyond Words. London and New York: Routledge.

Burns J (2009) An Interpretive Description of the Patterns of Practice of Arts Therapists working with Older People who have Dementia in the UK. Unpublished PhD Thesis, Queen Margaret University. Department of Occupational Therapy and Arts Therapies, Edinburgh, UK.

Byrne P (1995) From the Depths to the Surface: Art Therapy as a Discursive Practice in the Post-Modern Era, The Arts in Psychotherapy, 22, 3, 234-239.

Chaiklin, S. and Schmais, D. (1986) The Chace approach to dance therapy. In P. Lewis (ed) Theoretical approaches in dance/movement therapy. V1 1. Iowa: Kendall/Hunt.

Clarkson, P. (1994) The Nature and Range of Psychotherapy. In P. Clarkson and M. Pokorny (eds.) The Handbook of Psychotherapy. London and New York: Routledge, $3-27$

Damasio, A. 2005. Descartes' Error: Emotion, Reason, and the Human Brain. London: Penguin Books.

Damasio, A. 2000. The Feeling of What Happens: Body and Emotion in the Making of Consciousness. London: Harvest Books.

Dosamantes- Beaudry, I (1997) Reconfiguring identity, The Arts in Psychotherapy, $24,1,51-57$.

Dosamantes-Alperson E. (1981) Experiencing in movement therapy, American Journal of Dance Therapy, 4(2) 33-44.

Gergen K J (1985)The Social Constructionist Movement in Modern Psychology, American Psychologist, 40, 3, 266-275.

Gazzola, V. Aziz-Zadeh, L. and Keysers, C. (2006) Empathy and the Somatotopic Auditory Mirror System in Humans. Current Biology, 16, 1824-1829

Gergen K J (1991) The Saturated Self. New York: Basic Books

Giacomo Rizzolatti et al. (1996) Premotor cortex and the recognition of motor actions, Cognitive Brain Research 3 131-141

Gordon, R. (1987) Playing on many stages: Dramatherapy and the individual. In S. Jennings (ed) Dramatherapy: theory and practice 1. London: Routledge, pp. 119-45.

Grentz S (1996) A Primer on Postmodernism. Grand Rapids, MI: William B Eermans.

Halprin D (2003) The expressive body in life, art and therapy: working with movement, metaphor and meaning. London: Jessica Kingsley. 
Hargreaves, D.J. (1982) The development of aesthetic reactions to music, Psychology of Music, special Issue: 51-54.

Jones P (1996) Drama as Therapy: Theatre as Living. London: Routledge

Karkou V. (2010) Research in Arts Therapies: On the Way towards Evidence-Based Practice and Practice-Based Evidence, in 1st Moscow International Arts Therapies Conference Building the Present - Looking into Future: Arts Therapies in the Modern World, Moscow, May 14-16, 2010, Organised by the Russian Art Therapy Association, the International Art Therapy Journal "The Healing Art", the Psychological Stock Exchange and the Russian State Social University

Karkou V. (2009) Evidence Based Practice and Practice Based Evidence in Arts Therapies, keynote speech at the $7^{\text {th }}$ international arts therapies conference Contemporary Arts Therapies - Theory and Practice, 17-19/07/09, Riga Stradins University, Cesis, Latvia

Karkou V (1998) A Descriptive Evaluation fo the Practice of Arts Therapies in the UK. Unpublished PhD Thesis, Univeristy of Manchester, School of Education.

Karkou, V, Martinsone K and Nazarova N (submitted 2010) Art Therapy in the Postmodern World: Findings from a Comparative Study across the UK, Russia, and Latvia, The Arts in Psychotherapy.

Karkou V Fullarton A and Scarth S (2010) Finding a Way out of the Labyrinth through Dance Movement Psychotherapy: Collaborative Work in a Mental Health Promotion Programme for Secondary Schools, V Karkou (ed) Arts Therapies in Schools: Research and Practice, London: Jessica Kingsley, pp.59-84.

Karkou V and Glasman J (2004) Arts, Education and Society: The Role of the Arts in Promoting the Emotional Well-being and Social Inclusion of Young People, Support for Learning, 19, 2, 56-64.

Karkou V and Sanderson P (2006) Arts Therapies: A Research-Based Map of the Field. Edinburgh: Elsevier.

Karkou V. and Sanderson P. (2001) Dance Movement Therapy in the UK: Current Orientations of a Field Emerging from Dance Education, European P.E. Review 2 7, 2, 137-155.

Karkou V. and Sanderson P. (2000) Dance Movement Therapy in UK Education, Research in Dance Education, 1, 1, 69-85.

Kestenberg, J. (1975) Children \& Parents: Psychoanalytic Studies in Development. New York: Jason Aronson.

Koch S C and Bender S (2007) Movement Analysis: The Legacy of Laban, Bartenieff, Lamb and Kestenberg. Berlin: Logos. 
Koch S C and Brauninger I (2006) Advances in Dance/Movement Therapy:

Theoretical and Empirical Findings. Berlin: Logos.

Laban R (1975) Modern Educational Dance. London: MacDonald and Evans.

Landy, R. (2001) Establishing a model of communication between an arts-based discipline and its applied creative art therapy. In Kossolapow, L Scoble, S. and Waller, D. (eds.) Arts - Therapies - Communication: On a way to a communicative European Arts Therapy, vol. 1. Munster: Lit Verlag, 305-310.

Levinge A (199) Permission to Play: the search for self through Music Therapy; Research with children presenting with communication difficulties. In H. Payne (ed) Handbook of inquiry in the Arts Therapies: One River, Many Currents. London and Philadelphia: Jessica Kingsley, pp. 218-228.

Levy, F. (1988) Dance Movement Therapy: A Healing Art. Reston: American Alliance for Health, Physical Education, Recreation and Dance.

Lyotard J F (1979 trans 1984) The Postmodern Condition. Manchester: Manchester University Press.

Malchiodi, C. (1998) The art therapy sourcebook. Los Angeles: Lowell House.

Martinsone K., Karkou V. and Nazarova N. (2009) Art Therapy Practice in Latvia, in the UK and in Russia: A Comparison of different Environments of Work. Collection of Scientific Papers 2009, Riga: Riga Stradins University, pp155-161.

McNeilly, G. (1983) Directive and Non-Directive Approaches in Art Therapy, The Arts in Psychotherapy, 10(4): 211-219.

Meekums B (2009) Moving towards evidence for dance movement therapy: Robin Hood in dialogue with the King, The Arts in Psychotherapy, 37, 1, 35-41

Meekums B (2002) Dance Movement Therapy: A Creative Psychotherapeutic Approach. London: Sage.

Meekums B (2000) Creative Group Therapy for Women Survivors of Child Sexual Abuse., London: Jessica Kingsley.

Meekums, B. Karkou, V. Elefant, C. Nundy-Mala, A. and Nelson, A. (2010) A review of the effectiveness of dance movement psychotherapy for dealing with depression.

Meier W (2008) Dance Movement Therapy: My Story, e-motion, XVIII, 2, 11-12. National Health Service (NHS) (2010) Agenda for Change. Retrieved: 01/10/10 From: http://www.nhsemployers.org/PayAndContracts/AgendaForChange/Pages/AfcHomepage.aspx

Nordoff P and Robbins C, (1977) Creative Music Therapy. New York: Harper \& Row Publishers. 
Nordorff P and Robbins C, (1971) Therapy in music for handicapped children. London: Voctor Gollancz.

North M (1972) Personality Assessment Through Movement. Plymouth: Northcote House.

Odell-Miller H (2002) One Man's Journey and the Importance of Time in Music Therapy. In A Davies and E Richards (eds) Music therapy and Group Work: Sound Company. London: Jessica Kingsley, pp. 63-76.

Odell-Miller H (2000) Music Therapy and its Relationship to Psychoanalysis. In Y Searle and I Sterng (eds) Where Analysis Meets the Arts. London: Karnac, pp. 127152

Oldfield A, (1995) Communicating through Music: The Balance between Following and Initiating. In T. Wigram, B. Saperston and R. West (eds) The Art and Science of Music Therapy: A Handbook. Switzerland: Harwood Academic Publications, pp. 226-237.

Pavlicevic M (1997) Music Therapy in Context: Music, Meaning and Relationship. London: Jessica Kingsley.

Payne H (1994) Dance Movement Therapy. In D Jones (ed) Innovative Therapy. Milton Keynes: Open University.

Payne H (1992) Introduction. In H Payne (ed) Dance Movement Therapy: Theory and Practice. London: Routledge, pp.1-17

Penfield, K. (1992) Individual Movement Psychotherapy: Dance Movement Therapy in Private Practice, in H. Payne (ed.) Dance Movement Therapy: Theory and Practice. London and New York: Tavistock/Routledge, pp. 163-182.

Perls F., Hefferline, R, Goodman P (1969) Gestalt Therapy: Excitement and Growth in the Human Personality. New York: Julian Press.

Priestley M. (1995) Linking Sound and Symbol. In T. Wigram, B. Saperston and R. West (eds.) The Art and Science of Music Therapy: A Handbook. Switzerland: Harwood Academic Publishers, pp..

Priestley M. (1975) Music Therapy in Action. London: Constable and Company Ltd, pp. .

Quality Assurance Agency (QAA) and National Health Service (NHS)(2004) Subject benchmark statement: healthcare programmes, phase 2: Arts Therapy, QAA 05909/04. Retrieved 01/10/10 From:

http://www.qaa.ac.uk/academicinfrastructure/benchmark/health/artsTherapy.asp\#natu $\underline{\text { re }}$

Reich W (1960) An Introduction to Orgonomy: Selected Writings. New York: Noonday. 
Rohricht F (2009) Body oriented psychotherapy. The state of the art in empirical research and evidence-based practice: A clinical perspective, Body, Movement and Dance in Psychotherapy, 4, 2, 135-156.

Sandel, S. and Johnson, D. (1983) Structure and Process of the Nascent Group: Dance Movement Therapy with Chronic Patients, The Arts in Psychotherapy, 10: 131-140.

Sanderson, P. (1996) Dance within the National Physical Education Curriculum of England and Wales, The European Physical Education Review, 2(1): 54-63.

Sanderson, P. (2001) Age and gender issues in adolescent attitudes to dance, European Physical Education Review, 7(2): 137-155

Sherborne V, (1990) Developmental movement for children. Cambridge: Cambridge University Press.

Shreeves R (2006) Full Circle: From choreography to dance movement therapy and back. In H Payne (ed) Dance Movement Therapy: Theory, Research and Practice. London: Routledge, 232-244.

Siegel, E. V. (1984) Dance movement therapy: Mirrors of ourselves. The psychoanalytic approach. New York: Human Sciences Press.

Smitskamp, H. (1995) The Problem of Professional Diagnosis in the Arts Therapies, The Arts in Psychotherapy, 22(3): 181-187.

Standley J M, (1991) The role of music in pacification/stimulation of premature students with low birth weights. Music Therapy Perspectives, 9, 19-25

Stanton- Jones, K. (1992) An introduction to dance movement therapy in psychiatry. London: Tavistock/Routledge.

Swanwick K and Tillman J (1986) The sequence of musical development: a study of children's composition, British Journal of Music Education 3(3): 305-339.

Thaut M H, (1985) The use of auditory rhythm and rhythmic speech to aid temporal muscular control in children with gross motor dysfunction. Journal of Music Therapy, 22 (3) 129-145.

Thorne, F C (1967) Integrative Psychology. Brandon VT: Clinical Publishing.

Trevarthen C and Aitken K J (2001) Infant Intersubjectivity: Research, Theory and Clinical Application, Journal of Psychology and Psychiatry, 42, 1, 3-48.

Tyler H (2000) The music therapy profession in modern Britain. In P Horden (ed) Music as Medicine: The history of music therapy since antiquity. Aldershot: Ashgate, pp.. 
Valente L and Fontana D (1993) Research into Dramatherapy: Theory and practice: Some Implications for Training. London: Jessica Kingsley, pp.56-67.

Waller, D. (1991) Becoming a profession: the history of art therapy in Britain 19401982. London and New York: Tavistock / Routledge.

Walrond-Skinner S (1986) Dictionary of Psychotherapy. London: Routledge and Kegan Paul.

Whitehouse, M., C. G. (1979) Jung and dance-therapy: two major principles. In P.L. Bernstein (ed) Eight theoretical approaches in dance/movement therapy, Vol. I. Iowa: Kendall/Hunt.

Wigram T, (1996) The effect of vibroacoustic therapy on clinical and non-clinical populations. Unpublished PhD Psychological research thesis. St George's Medical School, University of London.

Wigram T and Dileo C (1997) (eds) Music, vibration and health. New Jersey: Jeffrey Books.

Wigram T, Pedersen I N and Bonde L O (2002) A Comprehensive Guide to Music Therapy: Theory, Clinical Practice, Research and Training. London: Jessica Kingsley.

Winnicott, D. W. ((1971) Playing and reality. London and New York: Routledge. 